This document is the accepted manuscript version of the following article:

Allegrini, J., Dorer, V., \& Carmeliet, J. (2015). Influence of morphologies on the microclimate in urban neighbourhoods. Journal of wind Engineering and Industrial Aerodynamics, 144, $108-117$. http://doi.org/10.1016/j.jweia.2015.03.024

This manuscript version is made available under the CC-BY-NC-ND 4.01 icense http://creativecommons.org/1icenses/by-nc-nd/4.0/

\title{
Influence of morphologies on the microclimate in urban neighbourhoods
}

\author{
${ }^{a}$ Laboratory for Building Science and Technology \\ Swiss Federal Laboratories for Materials Science and Technology (Empa) \\ Überlandstrasse 129, 8600 Dübendorf, Switzerland \\ ${ }^{b}$ Chair of Building Physics, Swiss Federal Institute of Technology Zurich (ETHZ), \\ Stefano-Franscini-Platz 5, 8093 Zürich, Switzerland
}

\section{Abstract:}

In the past decades the portion of the population living in urban areas has continuously increased. Due to the high building density, the microclimate in urban areas changes significantly compared to rural areas. The temperatures measured in urban areas are higher compared to the rural temperatures due to the urban heat island (UHI) effect. Furthermore, the longwave and solar radiation exchanges are influenced by shadowing, reflections between buildings and reduced sky view factors. The local urban microclimate has an influence on the energy demand of buildings and on human comfort and health in urban areas. In summer the human comfort in urban areas can decrease due to higher air and surface temperatures and lower wind speeds compared to rural areas. The local urban microclimate is difficult to predict because of the complex interaction of physical phenomena across a large range of time and length scales. Few guidelines exist for architects to mitigate UHI effects or its impacts. The aim of this paper is to model the urban microclimate with CFD and building energy simulations and to investigate in detail the influence of different urban building morphologies on the urban microclimate. This approach and the results of this study can be used to find measures to mitigate the UHI effect. The results show that building façade surface temperatures are mainly influenced by the distance between buildings. For urban morphologies with similar surface temperatures, the air temperatures can still strongly vary due to different wind flow patterns causing different rates of removing heat by wind.

\section{Keywords}

Urban heat island effect, CFD, Building energy simulation, Comfort, Microclimate, Urban design Corresponding author: Jonas Allegrini, Empa Dübendorf, Ueberlandstrasse 129, 8600 Dübendorf, Switzerland. Tel.: +41 (0) 587656512 , Fax: +41 (0) 5876540 09, e-mail: jonas.allegrini@empa.ch

Number of words: 6776 


\section{Introduction}

The microclimate in urban areas differs significantly from the climate in rural areas. The air temperatures are higher due to the urban heat island (UHI) effect and the wind speeds are, on the average lower due to wind sheltering (Oke 1987). The UHI effect is mainly caused by storage of solar heat in built construction materials with high heat capacity, reduced longwave radiation to the sky by reduced sky view factors, generation of anthropogenic heat, lack of evapotranspiration and reduced turbulent convection to remove heat (Santamouris 2001a). Measurements in London showed up to $7 \mathrm{~K}$ higher air temperatures at night-time in the city compared to measurements outside the city (Watkins et al. 2002). In Athens the mean heat island intensity exceeds $10 \mathrm{~K}$, which can double the energy demand for space cooling in buildings (Santamouris et al. 2001b). Future global warming and associated heat waves (Schär et al. 2004; Fischer and Schär, 2009) may further increase the temperatures in urban areas and can reduce the potential for passive night cooling significantly. The UHI effect not only influences the energy demand for air conditioning, but has also a large impact on the thermal comfort and health of the people living in urban areas.

Knowledge of the detailed urban microclimate is important for a wide number of applications. For example to get accurate results for building energy simulations, accurate microclimatic data at the building site are needed. Also city planners need finely resolved climatic data to improve the thermal comfort in existing urban areas or for planning new urban areas with high thermal comfort. For most cities the available climatic data are limited to very few measurement points. Besides local measurements, numerical simulations can be used to predict and study the local microclimate at the neighbourhood scale. Numerical simulations have the advantage that different building configurations can be evaluated to improve the local microclimate. Therefore results from numerical simulations can help city planners to decide on parameters like the building density or building geometries etc. for new urban areas. In literature the local urban microclimate is numerically studied with different degrees of complexity. For different scales different numerical models have to be applied. In a large number of studies ENVI-met (Bruse and Fleer, 1998) is used to simulate the urban microclimate. ENVI-met is a model including the simulation of flows around buildings, exchange processes of heat and vapour, turbulence, impact of vegetation, bioclimatology and pollutant dispersion (Bruse and Fleer, 1998). Typical spatial resolutions are $0.5-10 \mathrm{~m}$ in space and $10 \mathrm{~s}$ in time. For the flow the 3D Navier-Stokes equations are solved with a k- $\varepsilon$ turbulence model. The spatial resolution is relatively low, therefore no boundary layer is resolved at the surfaces, which makes it impossible to determine the wall heat fluxes at building façades from the flow simulations. Instead correlations of convective heat transfer coefficients are used. Alternatively also wall functions can be used to model the boundary layer, but are not implemented in ENVI-met. For the radiation a simplified model is used that describes how much the incoming radiation is reduced by buildings and plants. Using this method, Ali-Toudert and Mayer (2006) studied the local microclimate in street canyons for dry and hot climates. The focus was mainly on the aspect ratio and orientation of the street canyons and they found considerable influence of these two parameters on the thermal comfort inside 
the street canyons. Perini and Magliocco (2014) studied with ENVI-met the effect of vegetation on the thermal comfort in densely built urban areas. They show that with vegetation on ground and roofs, the air temperatures in summer can be reduced, the thermal comfort can be improved and energy for air conditioning can be saved. Taleghani et al. (2014) compared the local microclimate for different urban morphologies. This study shows that mainly shadowing is important for improving the thermal comfort. Orehounig et al. (2014) studied the effects of future climate change, building and vegetation configurations for a new urban development project in the city of Vienna using meso-scale weather models, ENVI-met and building energy simulation (BES). In conclusion these works show that ENVI-met can solve a wide number of physical phenomena numerically and can be applied to different urban configurations. However, to be able to solve all these phenomena, simplified numerical models have to be used and the spatial resolution has to be rather low. Therefore the accuracy is lower compared to other numerical models, which use more advanced numerical models and have higher spatial resolution, but need more computational power or can only solve for a smaller number of physical phenomena.

MITRAS (Schlünzen et al. 2003) is a microclimate model that was developed to study the local microclimate in urban areas. MITRAS is based on a mesoscale model, but is able to resolve obstacles. In addition to wind, temperature, humidity and tracer concentrations also equations for cloud- and rainwater and for chemical reactions are solved. Bohnenstengel et al. 2004 conducted simulations with MITRAS to study the influence of thermal effects on street canyon circulations. They found that the large scale thermal stability has a strong influence on the circulation inside the street canyon. Schlünzen et al. 2011 showed how MITRAS can be coupled with mesoscale models to account for the large-scale phenomena in microclimate simulations and the influence of obstacles on the mesoscale simulations. Also MITRAS has a rather low typical spatial resolution of a few meters (e.g. $4 \mathrm{~m}$ in the study of Bohnenstengel et al. 2004 or $2.5 \mathrm{~m}$ in the study of Grawe et al. 2013). The advantage of conducting more detailed CFD (computational fluid dynamics) simulations (e.g. STAR-CCM, OpenFOAM, ANSYS Fluent) is that the domain can be resolved with a much higher spatial resolution and more accurate models can be used, however the computational costs are increased. To determine accurately the convective heat transfer at the building façades, Saneinejad et al. (2012) conducted CFD (computational fluid dynamics) simulations coupled with a detailed radiation model and heat and moisture transport model for porous media for a two-dimensional urban street canyon. With this more complex approach, more detailed and accurate results can be obtained compared to more simplified models (e.g. ENVI-met), but also more computational power is needed. Studies with a similar approach have been conducted to investigate the influence of the local microclimate on the space cooling demand of buildings in urban areas (eg. Allegrini et al. 2012a; Bouyer et al. 2011). Toparlar et al 2014 conducted a case study for an urban area in Rotterdam, where they used a commercial CFD code (ANSYS Fluent) to study the urban microclimate considering the wind flow and the radiative heat fluxes. A similar study was conducted by Santiago et al 2014, who used CFD to simulate the wind flow and their own numerical model to determine the radiative heat transfer. Tominaga (2012) evaluated the 'breathability' of urban areas with CFD. The 
urban areas consisted of buildings with square footprints and different building heights. The results show high variability of the local air temperature and wind speeds depending on the heights of the individual buildings. CFD is not only used for studies at the neighbourhood scale; CFD with low spatial resolution is also used at city scale (e.g. Mochida et al. 1997; Ashie and Kono, 2011).

In this paper an approach (similar to the approach of Santiago et al. 2014) to simulate the local microclimate by coupling BES with CFD simulation is applied. CFD simulations are conducted to get accurate microclimatic results with high spatial resolution. Mainly two aspects are studied in this paper: (a) building surface temperatures and (b) outdoor air temperatures. The surface temperatures are important for the thermal performance of the buildings and for the thermal comfort of the pedestrians, the air temperatures are also important for the thermal comfort of the pedestrians as well as for the ventilation of the buildings. Compared to Tominaga (2012), who imposed the same temperature for all the building surfaces, here the building surface temperatures are different and simulated with a BES model. Simulations are conducted for different generic urban morphologies.

The structure of the paper is as follows. The different urban morphologies and the configuration of the buildings studied are given in Section 2. In Section 3 the numerical models of BES and CFD are presented. In Section 4 the simulation results are presented. First the surface temperatures determined with BES for the different morphologies are compared. Then results of CFD simulations are presented for weather conditions for two different wind speeds leading to high surface temperatures. Finally the air temperatures determined with CFD are analysed. In Section 5 the obtained results are discussed and in Section 6 the conclusions are drawn.

\section{Numerical model}

The simulations presented in this paper are conducted for 6 different urban morphologies (Figure 1) for the climate of Zürich (Switzerland). Five morphologies are typical for Swiss cities and one morphology is more generic (bottom left in Figure 1). The number of buildings for each morphology is limited by the computational power that is needed for the CFD simulations. All buildings are modelled as office buildings with corresponding occupancies and internal gains (SIA 2006). Ventilation and infiltration are considered (ventilation: depending on outside air temperature and window openable fraction; infiltration: air change rate of $0.15 \mathrm{~h}^{-1}$ ). The glazing (G-value: $0.7, \mathrm{U}$-value: 1.1 $\mathrm{W} / \mathrm{m}^{2} \mathrm{~K}$ ) fraction of the buildings is $50 \%$ and all façades have a solar reflectance of 0.5 . The walls have a U-value of $0.25 \mathrm{~W} / \mathrm{m}^{2} \mathrm{~K}$ (with outer insulation), the roofs have a U-value of $0.29 \mathrm{~W} / \mathrm{m}^{2} \mathrm{~K}$ and the floors a U-value of $0.3 \mathrm{~W} / \mathrm{m}^{2} \mathrm{~K}$. External shading devices are used to protect the buildings from solar gains. They close when the solar irradiation on the corresponding façade is $>150 \mathrm{~W} / \mathrm{m}^{2}$ and reopen when it is $<50 \mathrm{~W} / \mathrm{m}^{2}$. Each building consists of five thermal zones. Each thermal zone consists of one exterior building wall (or roof) and the associated part of the building volume. The five zones are assumed to be maintained at the same inside air temperature. Space heating and space cooling are used to keep the inside air temperature between $21^{\circ} \mathrm{C}$ and $26^{\circ} \mathrm{C}$. All buildings have a height $(\mathrm{H})$ and a width $(\mathrm{W})$ of $10 \mathrm{~m}$ and are between $10 \mathrm{~m}$ and $70 \mathrm{~m}$ long (L). For one case (Figures 4 and 5) some buildings have a height of $20 \mathrm{~m}$. The distance between the buildings (D) is $10 \mathrm{~m}$, 
leading to a canyon aspect ratio (H/D) of 1 . For the street canyon case, an additional simulation using an aspect ratio of 2 is conducted. The ground surface between the individual buildings is modelled as asphalt. Yearly BES are conducted with an hourly timestep.

CFD simulations are conducted for a weather condition with a rather high ambient air temperature of $25.5^{\circ} \mathrm{C}$ on $2^{\text {nd }}$ of July and high solar irradiation. This weather condition was chosen due to the rather high temperatures and the northerly wind direction for the higher wind speed case (see below). For the lower wind speed case the same temperatures are used to have the same temperature boundary conditions for the comparison. At ground and building surfaces the temperatures as determined by the BES are imposed. The ground temperature outside the urban area is set to the ambient air temperature to avoid heating up the air in the approach flow. For the near-wall modelling, standard wall functions (Launder and Spalding 1974) with no-slip boundary condition are used as a compromise between accuracy and computational cost. The standard wall functions are commonly used for CFD simulations of urban areas, although it is known that the use of wall function can lead to an overestimation of the convective heat flux at the building facades and subsequently to an overestimation of the local air temperatures (Allegrini et al. 2012b). For accurate heat transfer predictions very fine meshes close to surfaces are needed, but with these meshes the surface roughness cannot be accurately modelled, because the cells height has to be much higher than the roughness. Therefore, in this study walls are modelled as smooth walls (no roughness; equivalent sand-grain roughness height $\mathrm{k}_{\mathrm{s}}=0 \mathrm{~m}$ ), what can lead to an underestimation of the connective heat transfer. However, the error made by using wall functions for smooth surfaces is assumed to be less than the influence of for example different material properties on the local heat island intensities. The aim of this paper is compare the microclimate for different cases using the same models with the same limitations.

At the inlet of the computational domain vertical profiles of the mean horizontal wind speed, the turbulent kinetic energy and the turbulence dissipation are imposed for two reference wind speeds at $10 \mathrm{~m}$ height, $1 \mathrm{~m} / \mathrm{s}$ and $5.5 \mathrm{~m} / \mathrm{s}$. These profiles represent a neutral atmospheric boundary layer, where the turbulence originates only from friction and shear (Richards and Hoxey, 1993):

$$
\begin{aligned}
& U(y)=\frac{u_{A B L}^{*}}{k} \ln \left(\frac{y+z_{0}}{z_{0}}\right) \\
& k(y)=\frac{u_{A B L}^{*}}{\sqrt{C_{\mu}}} \\
& \varepsilon(y)=\frac{u_{A B L}^{*}}{k\left(y+z_{0}\right)}
\end{aligned}
$$

Here $\mathrm{u}_{\mathrm{ABL}} *$ is the atmospheric boundary layer friction velocity, $\mathrm{y}$ the height above the ground, $\mathrm{z}_{0}$ the aerodynamic roughness length, $\mathrm{k}$ the turbulent kinetic energy, $\varepsilon$ the turbulence dissipation rate, $\mathrm{U}$ the mean streamwise velocity and $\mathrm{C}_{\mu}$ a constant of the turbulence model.

Neutral atmospheric boundary layers are commonly used to model the approach flow profiles of the velocity, turbulent kinetic energy and the turbulence dissipation for CFD simulations of urban flows. In reality the atmospheric boundary layer may be unstable stratified especially for weather conditions with high temperatures and low wind speeds. The results of this study should be inter- 
preted with care since the simulations were only conducted with neutral atmospheric boundary layers. In future studies the results will be compared with results of simulations using unstable boundary layers to study the influence of the approach flow boundary layers on the flow inside the urban areas. Bohnenstengel et al. 2004 showed that the stability of the atmospheric boundary layer can influence the flow in urban street canyons.

At the sides and top of the computational domain a symmetry boundary condition is applied. At the outlet an outflow boundary condition is used, which assumes that there are no streamwise gradients at the outlet.

The computational domain extends $5 \mathrm{H}$ upstream and $10 \mathrm{H}$ downstream of the building group. In vertical direction the domain is $10 \mathrm{H}$ high. These dimensions are in agreement with best practice guidelines (Franke et al. 2011; Tominaga et al. 2008).

Structured grids are built based on a grid sensitivity analysis. The grids consist of $3.7-9.9$ million cells and are refined towards the walls to resolve the boundary layers. For the lower wind speed used in this study, the $y+$ values were $<500$; for the higher wind speed, $y+$ values up to 1500 can be found locally. It was found by conducting simulations with a finer (for the street canyon case 8.5 million cells) and a coarser (for the street canyon case 2.5 million cells) mesh, that the rather high $y+$ values did not cause grid dependent results for the wind speeds and temperatures. The maximum difference of velocity magnitudes between simulations with the coarse mesh and the mesh used in this study (for the street canyon case 3.7 million cells) for the flow between the buildings was $4 \%$. For the temperatures a difference up to $0.2 \mathrm{~K}$ was found. These differences reduced to $0.2 \%$ and $0.05 \mathrm{~K}$, when comparing the results between the mesh of this study and the fine mesh. These values are small compared to the differences found between the two cases for this study. The same parameters for the grid generation were used for all configurations and therefore the grid sensitivity analysis gave very similar results for all cases.

\section{Numerical simulation}

\subsection{Radiation and building energy simulation}

For the BES CitySim (Kämpf 2009) is used. CitySim is a simulation tool which models the energy fluxes in a city, with size ranging from a small neighbourhood to an entire city. In CitySim detailed radiation models for solar and longwave radiation are implemented that can account for the radiation exchange between neighbouring buildings, the ground and environment. The Perez All Weather (Perez et al. 1993) and Simple Radiosity algorithm (Robinson and Stone, 2006) are used to compute hourly irradiations of short and longwave radiation on building surfaces. Multiple iterations for the radiation calculations are performed within one timestep to reach converged values of the surface temperatures, avoiding oscillations between different timesteps. The heat flow through the walls is determined with a model based on the analogy with an electrical circuit (resistor-capacitor network). For the heat conduction calculations, the windows are not represented geometrically, so no window surface temperature is determined and the temperature for the whole façade is assumed 
to be the temperature of the wall. For the convective heat transfer coefficients (CHTC) CitySim uses the correlations by McAdams (1954). Because the CHTC are not an input in the current CitySim version, the heat fluxes from the CFD simulations of this study cannot be used in CitySim. Based on the paper by Allegrini et al. (2012c) it is assumed that no large errors are introduced by using these CHTC correlations. CitySim uses an hourly timestep, which cannot be changed. To get individual temperatures for the individual façades and the roof of a building, each building is modelled in BES as a multizone building with a zone for each façade and roof. CitySim includes HVAC and energy conversion system models (Robinson, 2011). In addition to the standard CitySim version the heat balance is solved for the ground surfaces between the buildings. This heat balances includes short and longwave radiation as well as heat conduction and storage of heat into the soil. To model the heat storage and heat conduction of the ground, a number of ground layers are defined with the thickness, the heat conductivity and the heat capacity as input parameters.

\subsection{CFD}

To study the urban microclimate, 3D steady RANS (Reynolds-Averaged Navier-Stokes) CFD simulations are conducted with a $k-\varepsilon$ turbulence model $\left(\mathrm{C}_{\mu}=0.09\right)$ with OpenFOAM. To account for buoyancy the Boussinesq approximation is used. Second-order discretization schemes as well as the SIMPLE algorithm for pressure-velocity coupling are employed. Pressure interpolation is of second order.

\section{Results}

\subsection{Building energy simulations}

In this section the results of the BES are presented and discussed. Figure 2 shows the evoluation in time of the absorbed solar, longwave and total radiation. Each curve represents the absorbed radiation on a façade with one orientation. Only the facades inside the urban area are considered and the results are not shown for the façades at the outer boundary of the urban area. The radiation on façades with the same orientation mostly coincides. Only for very low solar angles (morning and evening) some small differences on the East, West and North façades can be found. The radiation on façades of different buildings is very similar due to the regular arrangement of the buildings. For the buildings close to the outer boundary of the urban area slightly higher solar absorption are found for low solar angles, because there is less shadowing from neighbouring buildings. During the day the absorbed solar radiation is larger than the outgoing longwave radiation leading to positive values for the total radiative heat flux for all façades. The peaks for the absorbed solar radiation are higher for the East and West façades compared to the North and South façades, because the angles of the direct solar radiation hitting the façades are higher. The longwave radiation is always negative for all façades, because for the time period shown heat is radiated to the cold sky. For the North, East and West façades the outgoing longwave radiation is decreased due to the incoming longwave radiation from the sunlit neighbouring façades. The peaks for the total radiative heat 
fluxes have similar magnitude for the East, West and South façades. For the North façades the peaks are lower, because they are always shaded.

Figure 3 depicts the wall surface temperatures of four different urban morphologies for a summer day. The general trends are very similar for the four orientations. The curves for the same urban morphology mostly coincide, meaning that all the surfaces with the same orientation inside the urban area have the same surface temperature. This is due to the uniform building height and uniform distance between the buildings. The temperatures for different urban morphologies are also very similar. Surface temperatures are found not to be influenced for example by constructing elongated buildings instead of cubical buildings. For the narrow street canyon (aspect ratio 2) the surface temperatures are lower on the East and West façades compared to the other geometries due to more shadowing especially in the morning and evening. For the South façades the temperatures are similar for the street canyons with the two aspect ratios, because for both geometries the whole façades are sunlit for the same time. All temperatures on the North façades are close to the ambient temperature, because they are not sunlit at all.

The results in Figure 3 are for a time period of $24 \mathrm{~h}$. Next, results for the whole year are studied. Figure 4 shows the cumulative number of hours per year that the difference between the surface and ambient temperature is larger than a given value (only for surface temperature $>25^{\circ} \mathrm{C}$ ). The results are given for four morphologies: two with cubical buildings with uniform height but different distances, one with buildings with a complex geometry and one with square buildings with nonuniform building heights (see insets of the figures). Each curve represents a given façade inside the urban area. For all geometries the highest surface temperatures can be found for the south façades. The results for the East and West façades are very similar and the lowest temperatures can be found for the North façades. All four morphologies show similar distributions. For the two morphologies represented in the top figures, most curves (for the same orientation) coincide, due to the regular arrangement of the buildings. For the staggered building arrangement some façades have a slightly higher number of hours with higher temperature differences, because they are close to the boundary of the urban area. The differences between the different façades with the same orientations are higher for the morphologies with complex building geometries and non-uniform building heights. These differences are due to shadowing effects: not all façades inside the urban area with the same orientation are sunlit for the same number of hours during the day. This means that surface temperatures inside urban areas can be significantly influenced by the presence of buildings with complex geometries or non-uniform buildings heights. With the help of the distributions in Figure 4, geometries can be chosen which increase the thermal comfort for the whole year, not only for specific weather situations. Better thermal comfort inside urban areas is achieved when the chosen geometries allow strong winds close to warm surfaces. This can for example be achieved by a morphology type with non-uniform building heights. The surfaces of the taller buildings above the roof height of the smaller buildings will heat up most. They can be cooled more efficiently by wind, because the building density is lower compared to the density below the roof height of the smaller buildings. At the same time, the surface temperatures of the smaller buildings are lower due to shadowing. An- 
other option to get lower surface temperatures is to use different materials for different surfaces; dominant wind flow can thus more efficiently cool the surfaces that absorb more radiation.

In Figure 5 the mean curve and standard deviation curve over all façades inside the urban area for each urban morphology are given for the results shown in Figure 4. The mean results are similar for the different urban morphologies. The cubical buildings have a slightly higher number of hours with high surface temperatures, because there is less shadowing. For all cases, the standard deviations are relatively small compared to the mean values. This confirms the conclusion from above that the façades with the same orientation within the urban areas have very similar temperatures. For the East and West façades deviations are higher compared to the mean values than for the South façades. As discussed above the largest deviations can be found for the complex geometry and the urban area with non-uniform building heights.

\subsection{CFD}

In the previous section it was concluded that for the studied urban morphologies the surface temperatures are very similar. Therefore the local microclimate mainly depends on the wind flow patterns and on the total building surface area that is heated. In this section the results of the CFD simulations are presented. Figure 6 shows false-colour plots of the temperature difference between the local air temperature and the ambient air temperature for two wind speeds at a height of $1.75 \mathrm{~m}$.

For all cases the air temperature is higher inside the urban area. Local heat island intensities (temperature difference between local and ambient air temperature) of up to $2.5^{\circ} \mathrm{C}$ can be observed (see also Figure 8 ). These local heat island intensities can be important for pedestrian comfort, heat transfer at building façades and air intake temperatures for building ventilation systems. For urban areas with higher potential to remove heat by wind, the local heat island effects are lower. For example for the morphology with the aligned cubical buildings, the temperatures are significantly lower compared to the morphology with the staggered cubical buildings. The wind flow through the long canyons in the windward direction of the aligned cubical buildings increases the potential to remove heat. For both wind speeds the highest temperatures can be found for the morphology with courtyards, areas where the air can only be exchanged through the top plane of the courtyard. Comparing the results of the different wind speeds confirms that for the low wind speed buoyancy is much more important than for high wind speeds. The region with increased air temperatures downstream of the urban areas is shorter. Furthermore, more cold air can enter the urban areas from the lateral sides and less heat is trapped in vortices, as can be seen for example for the street canyon case. In Figure 7 streamlines for the street canyon case are given for the two wind speed cases to illustrate the two different flow patterns for the two wind speed cases. For the lower speed case air is entering the street canyons from the sides and is leaving the street canyons through the top plane. For the higher speed case a standing vortex can be found. More hot air can leave the street canyons through the shear layer, due to stronger buoyancy effects. Similar effects can be found for the courtyard case, where the temperatures in the streets between buildings are lower for the case with lower wind speeds, because cold air can enter the streets from the side. Inside the courtyard in the 
centre, the air temperatures are higher for the low wind speed case, because the air entering from the top is already heated from the buildings upstream. For the lower wind speed the hottest courtyards are in the middle row, whereas for higher wind speed the downstream rows are hottest. Also for the array of staggered cubical buildings, the air temperatures for the high wind speed case are significantly higher, because the buoyancy forces are not strong enough for the warmer air to leave the urban area through the top plane and the flow is blocked downstream due to the staggering of buildings. For the lower wind speeds the warm air is rising and due to the resulting suction effect cold air is entering from the side of the urban area leading to lower air temperatures. We remark that the lower air temperatures do not necessarily lead to better thermal comfort, because at the same time the lower wind speeds decrease the thermal comfort (see below).

Due to limited computing power, CFD simulations could be conducted for relatively small urban areas only. The results in Figure 6 show that the local air temperatures are increasing in the windward direction. Therefore for larger urban areas the local heat island intensities could be even higher further downstream.

In Figure 8 the distributions of the air temperatures are given for the two wind speeds.

As discussed above, it can be seen that the air temperatures are lower for the low wind speed cases compared to the higher wind speeds. Also the distributions are wider and the differences between the morphologies are bigger for the low wind speed cases. The two morphologies with more complex geometries have a wider distribution compared to the morphologies with cubical and elongated buildings. The distributions for the case with staggered buildings and with street canyons have similar slopes but different averaged temperatures. For the street canyons we see a higher increase in averaged temperatures with increasing wind speed compared to the other morphologies, because the blockage of the wind becomes more important. For the high wind speed cases the narrowest distribution can be found for the aligned cubical buildings, where the ventilation is highest. The high blockage of the wind for street canyons causes the widest distribution. For the courtyards the blockage is also high, leading to the highest temperatures, but the distribution is narrower compared to the street canyons, because less cold air can enter the urban area and therefore the lowest temperatures are also quite high.

Figure 9 depicts the averaged air temperature inside the urban areas as a function of an area weighted average of a non-dimensional distance between buildings $\left(\mathrm{L}_{\mathrm{f}}\right)$ :

$$
L_{f}=\frac{\int \frac{D_{x}}{L_{x}} d A+\int \frac{D_{y}}{L_{y}} d A}{2 A}
$$

Here $D_{x}$ is the distance in the $x$ direction to the buildings closest to the point $(x, y), L_{x}$ is the length of the urban area in $\mathrm{x}$ direction, $\mathrm{D}_{\mathrm{y}}$ is the distance in the $\mathrm{y}$ direction to the buildings closest to the point $(\mathrm{x}, \mathrm{y}), \mathrm{L}_{\mathrm{y}}$ is the length of the urban area in the $\mathrm{y}$ direction and $\mathrm{A}$ is the non-built area.

$\mathrm{L}_{\mathrm{f}}$ is a measure of how far the wind can flow freely until it hits a building wall. Here the main flow direction ( $\mathrm{x}$ ) of the wind and the direction normal to the mean flow direction (y) are considered, as- 
suming that those are the most important flow directions. Small $\mathrm{L}_{\mathrm{f}}$ values mean that the wind can only flow for short distances without being disturbed and therefore wind speeds are strongly decreased due to high blockage. This leads to higher air temperatures within the urban areas, as can be seen in Figure 9. There is a clear trend of higher averaged air temperatures within the urban areas for lower $\mathrm{L}_{\mathrm{f}}$. For example the urban morphology with aligned cubical buildings has lower averaged air temperatures than the urban morphology with staggered cubical buildings. The temperatures for the two morphologies with more complex geometries are deviating from the trend lines, because flow regimes get more complex. For the courtyards there are areas where the air can only be exchanged through the top and therefore the temperatures are higher than predicted by the trend line. On the other hand the temperatures for the urban morphology with four complex buildings are lower than expected, because the small number of buildings causes relatively large boundary effects. The trends are comparable for the two wind speeds studied. It can be concluded that the temperatures within urban areas can be decreased by creating larger areas with low blockage of the wind. As already remarked above, not only the temperature is important for the thermal comfort of pedestrians but also the wind speed. In Figure 10 false-colour plots of the velocity magnitude for two wind speeds at $1.75 \mathrm{~m}$ above the ground are given. For both wind speeds a wide range of local velocity magnitudes can be found. The velocity magnitudes are strongly reduced within the urban areas for all morphologies. For the higher wind speed case there are almost no accelerations within the urban areas. The long canyons that cross the whole urban area are the only places where no strong decrease of the wind speed can be observed. For the low wind speed case, for some areas higher velocity magnitudes compared to the freestream velocities occur inside the urban areas. This is mainly caused by buoyancy effects. For the same reason the area with strongly reduced wind speeds is smaller for the low wind speed case compared to the high wind speed case. Comparing Figure 6 with Figure 10 it can be seen that the regions with high local temperatures and low velocity magnitudes coincide. This leads to strongly decreased thermal comfort in those areas, because the higher air temperatures cannot be compensated by higher wind speeds.

Due to the importance of the air temperature and the wind speed for the thermal comfort, in Figure 11 for all the urban morphologies the averaged air temperature is given as a function of the averaged wind speed for both wind speed cases. Generally the averaged temperatures and averaged wind speeds are not correlated. Therefore higher averaged wind speeds do not necessarily lead to lower averaged temperatures. Here only averaged results are compared therefore it is not clear for which cases higher temperatures can be compensated by higher wind speeds. As mentioned above zones with high temperatures and zones with low wind speeds often coincide, which is the worst case. For the lower wind speed case the range of averaged velocities within the urban area is smaller compared to the high wind speed case. This is due to the stronger buoyancy effects for the low wind speed case which are of quite similar strength for all morphologies. It is rather surprising that for the high wind speed case the averaged wind velocities within the urban areas are similar for the aligned cubical buildings and the four complex buildings. This is probably again caused by the small number of buildings leading to relatively large boundary effects. 


\section{Discussion}

414

415

416

417

418

419

420

421

422

423

424

425

426

427

428

429

430

431

432

433

434

435

436

437

438

439

440

441

442

443

444

445

446

447

448

449

In this paper an approach for coupling BES with CFD simulations to study the urban microclimate was presented and results for a small number of urban morphologies was studied and understanding of the phenomena at play. The simulations show promising results. However this approach and the models used have some limitations and need to be further developed. Also to draw more general conclusions, a large number of additional simulations should be conducted.

The approach used for this study is only applicable for a small group of buildings and not for a city quarter or a whole city. This is on the one hand due to the high computational costs of the CFD simulations using fine meshes for resolving the wind flow patterns accurately. On the other hand the setting up of the BES is very time consuming, because the individual zones of each building have to be defined. Also due to the computational power needed for these kinds of simulations, the analysis can only be conducted for a limited number of weather conditions. To be able to analyse the thermal comfort for an urban area for a whole season, the weather conditions that are simulated have to be chosen carefully. To use the results from the CFD simulations to improve the climatic inputs for the BES, statistical emulation methods need to be applied (Evins et al. 2014), because the local microclimate cannot be simulated with CFD for each timestep of the BES. Also, to get more realistic surface temperature boundary conditions for the CFD simulations, BES and CFD simulations should be coupled. A BES should be conducted to get an initial guess. Then with CFD, CHTCs have to be determined and used again to conduct an updated BES. In future CitySim versions it will be possible to set the CHTC as an input. This process should be iterated between the two models until the results converge. Such coupling was used for a single street canyon geometry by Allegrini et al (2012c). It was not possible to perform coupled CFD-BES simulations due limitations in computational power and software limitations. Furthermore, each façade is modelled as a single surface element in CitySim with one temperature. No information on the temperature of the windows or blinds can be extracted from CitySim. To get more accurate results for the local microclimate, also the window or blind surface temperatures would be needed as boundary condition for the CFD simulations.

To study the urban microclimate in more detail, simulations with oblique flow should be conducted. Also a wider range of building geometries (e.g. non-uniform building heights or more detailed geometries of the individual buildings) could lead to additional information on the urban microclimate. Also, only steady CFD simulations were conducted here. With unsteady CFD simulations more accurate information on the ventilation potential of the urban areas could be gained (Moonen et al. 2011). Further, because only small groups of buildings were studied, the urban heat island intensities are underestimated, because the flow is not in equilibrium and the temperatures are still increasing in the flow direction. Also, in the small domain studied, cold air enters the urban areas from the side. For a city this might not be possible due to more buildings around the studied urban area. The cases studied here could rather correspond to a city where the dense urban areas are sur- 
rounded by parks to compensate for the dense areas. And finally, vegetation and effects of moisture are not considered.

\section{Conclusion}

An approach to model the urban microclimate and the results in terms of air temperatures for a number of urban morphologies are presented in this paper. A building energy simulation (BES) model is used to determine the surface temperatures of the buildings and the ground. In the BES model short and longwave radiation, convective heat transfer at the surfaces and heat conductance through the walls and ground are considered. CFD simulations are conducted to predict the local microclimate, where the surface temperatures determined with BES are used as boundary condition. The results show that there is a complex interaction between the buildings and the local microclimate. For urban morphologies with cubical or elongated buildings with uniform heights and constant distance between the buildings, the (surface) temperatures for the different façades are very similar. The façade temperatures are mainly influenced by the distance between the buildings and the presence of buildings with non-uniform heights. The façade temperatures are lowered when more complex geometries are present, what lead to increased shadowing effects. The façade temperature and shadowing effects not only influence the local microclimate around the buildings but also the space cooling and heating demands of the buildings. The wind flow study on air temperatures shows the presence of local heat island effects. Even with similar façade temperatures these heat islands have significantly different intensities depending on the potential of removing heat. Counterintuitively, the intensity of the local heat islands is higher for the cases with higher wind speeds for the small urban areas studied, where cold air can enter from the side of the domain. For the lower wind speeds buoyancy is more important and therefore the vertical heat exchange is enlarged. For thermal comfort in urban areas, besides the local temperature, the local wind speeds are also important. The wind speed inside the urban areas is strongly reduced and a wide range of wind speeds can be found within the urban areas. For most urban morphologies the zones for increased air temperatures and decreased wind speed coincide. Therefore in most cases the increasing air temperature cannot be compensated by a higher wind speed. Local areas with strongly decreased thermal comfort occur. In summary, there are a large number of parameters that influence the local microclimate leading to local heat islands and complex wind flow structures, which have an important effect on human comfort and the energy demand of buildings in urban areas.

Acknowledgments

Funding by EU Climate-KiC (Project Smart Urban Adapt) and CCEM (Project Urban Multi-scale Energy Modelling - UMEM) is gratefully acknowledged.

\section{References}

Ali-Toudert, F., Mayer, H., 2006. Numerical study on the effects of aspect ratio and orientation of an urban street canyon on outdoor thermal comfort in hot and dry climate. Build. Environ. 41, 94108. 
Allegrini, J., Dorer, V., Carmeliet, J., 2012a. Influence of the urban microclimate in street canyons on the energy demand for space cooling and heating of buildings. Energ. Buildings 55, 823-832.

Allegrini, J., Dorer, V., Carmeliet, J., 2012b. An adaptive temperature wall function for mixed convective flows at exterior surfaces of buildings in street canyons. Build. Environ. 49, 55-66.

Allegrini, J., Dorer, V., Carmeliet, J., 2012c. Analysis of convective heat transfer at building façades in street canyons and its influence on the predictions of space cooling demand in buildings. J. Wind En. Ind. Aerod. 104-106, 464-473.

Ashie, Y., Kono, T., 2011. Urban-scale CFD analysis in support of a climate-sensitive design for the Tokyo Bay area. Int. J. Climatol. 31, 174-188.

Bohnenstengel, S., Schlünzen, K.H., Grawe, D., 2004. Influence of thermal effects on street canyon circulations. Meteorologische Zeitschrift 13 (5), 381-386.

Bouyer, J., Inard, C., Musy, M., 2011. Microclimatic coupling as a solution to improve building energy simulation in an urban context, Energ. Buildings 43, 1549-1559.

Bruse, M., Fleer, H., 1998. Simulating surface-plant-air interactions inside urban environments with a three-dimensional numerical model. Environ Modell. Softw. 13, 373-384.

Evins, R., Allegrini, J., Moonen, P., 2014. Emulating site-specific wind flow information for use in building energy simulations. Building simulation and optimization conference, London.

Fischer, E.M., Schär, C., 2009. Future changes in daily summer temperature variability: driving processes and role for temperature extremes. Clim. Dynm. 33, 917-935.

Franke, J., Hellsten, A., Schlünzen, H., Carissimo, B., 2011. The COST 732 best practice guideline for CFD simulation o flows in the urban environment: a summary. Int. J. Environ. Pollut. 44 (1-4), 419-427.

Grawe, D., Schlünzen, K.H., Pascheke, F., 2013. Comparison of results of an obstical resolving mircoscale model with wind tunnel data. Atmos. Environ. 79, 495-509.

Kämpf, J., 2009. On the modelling and optimisation of urban energy fluxes, $\mathrm{PhD}$ thesis $\mathrm{n}^{\circ} 4548$ EPF Lausanne, Lausanne.

Launder, B.E., Spalding, D.B., 1974. The numerical computation of turbulent flows. Comput Method Appl M Eng 3, 269-289.

McAdams, W.H., 1954. Heat Transmission, McGraw-Hill Kogakusha, Tokyo.

Mochida, A., Murakami, S., Ojima, T., Kim, S., Ooka, R., Sugiyama, H., 1997. CFD analysis of mesoscale climate in the Greater Tokyo area. J. Wind En. Ind. Aerod. 67-68, 459-477.

Moonen, P., Dorer, V., Carmeliet, J., 2011. Evaluation of the ventilation potential of courtyards and urban street canyons using RANS and LES. J. Wind En. Ind. Aerod. 99, 414-423.

Oke, T.R., 1987. Boundary Layer Climates, second ed. Methuen, London. 
Orehounig, K., Mahdavi, A., Doppelbauer, E.M., Loibl, W., Tötzer, T., 2014. Projections of design implications on energy performance of future cities: A case study from Vienna. Sustain. Cities Soc. 12, 92-101.

Perez, R., Seals, R., Michalsky, J., 1993. All-weather model for sky luminance distribution preliminary configuration and validation. Sol. Energy 50 (3), 235-243.

Perini, K., Magliocco, A., 2014. Effects of vegetation, urban density, building height, and atmospheric conditions on local temperatures and thermal comfort. Urban For. Urban Gree. http://dx.doi.org/10.1016/j.ufug.2014.03.003.

Richards, P.J., Hoxey, R.P., 1993. Appropriate boundary conditions for computational wind engineering models using the k- $\varepsilon$ turbulence model. J. Wind En. Ind. Aerod. 46-47, 145-153.

Robinson, D., Stone, A., 2006. Internal illumination prediction based on a simplified radiosity algorithm. Sol. Energy 80 (3), 260-267.

Robinson, D., 2011. Computer Modelling for Sustainable Urban Design: Physical Principles,

Methods and Applications, Earthscan, London.

Saneinejad, S., Moonen, P., Defraeye, T., Derome, D., Carmeliet, J., 2012. Coupled CFD, radiation and porous media transport model for evaluating evaporative cooling in an urban environment. J. Wind En. Ind. Aerod. 104-106, 455-463.

Santamouris, M., 2001a. Energy and climate in the urban built environment, James \& James, Lon539 don.

Santamouris, M., Papanikolaou, N., Livada, I., Koronakis, C., Georgakis, A., 2001b. On the impact of urban climate on the energy consumption of buildings. Sol. Energy 70 (3), 201-216.

Santiago, J.L., Krayenhoff, E.S., Matilli, A., 2014. Flow simulations for simplified urban configurations with microscale distributions of surface thermal forcing. Urban Clim. 9, 115-133.

Schär, C., Vidale, P.L., Lüthi, D., Frei, C., Häberli, C., Liniger, M.A., Appenzeller, C, 2004. The role of increasing temperature variability in European summer heatwaves. Nature 427, 332-336. Schlünzen, K.H., Hinneburg, D., Knoth, O., Lambrecht, M., Leitl, B., Lopez, S., Lüpkes, C.,

547 Panskus, H., Renner, E., Schatzmann, M., Schoenemeyer, T., Trepte, S., Wolke, R., 2003. Flow and 548 Transport in the Obstacle Layer: First Results of the Micro-Scale Model MITRAS. J. Atmos. Chem. $549 \quad 44,113-130$.

550 Schlünzen, K.H., Grawe, D., Bohnenstengel, S.I,, Schlüter, I., Koppmann, R., 2011. Joint modelling 551 of obstacle induced and mesoscale changes - Current limits and challenges. J. Wind En. Ind. Aerod. 99 (4), 217-225. 
555 Taleghani, M., Kleerekoper, L., Tenpierik, M., Van den Dobbelsteen, A., 2014. Outdoor thermal 556 comfort within five different urban forms in the Netherlands. Build. Environ.

557 http://dx.doi.org/10.1016/j.buildenv.2014.03.014.

558 Tominaga, Y., Mochida, A., Yoshie, R., Kataoka, H., Nozu, T., Yoshikawa, M., Shirasawa, T., 559 2008. AIJ guidelines for practical applications of CFD to pedestrian wind environment around 560 buildings. J. Wind Eng. Ind. Aerodyn. 96, 1749-1761.

561 Tominaga, Y., 2012. Visualization of city breathability based on CFD technique: case study for ur562 ban blocks in Niigata City. J. Vis. 15, 239-276.

563 Toparlar, Y., Blocken, B., Vos, P., van Heijst, G.J.F., Janssen, W.D., van Hooff, T., Montazeri, H., 564 Timmermans, H.JP., 2014. CFD simulation and validation of urban microclimate: A case study for 565 Bergpolder Zuid, Rotterdam. Build. Environ. http://dx.doi.org/10.1016/j.buildenv.2014.08.004.

566 Watkins, R., Palmer, J., Kolokotroni, M., Littlefair, P., 2002. The London Heat Island - results 567 from summertime monitoring. Build. Serv. Eng. Res. Technol. 23 (2), 97-106. 


\section{Figures}

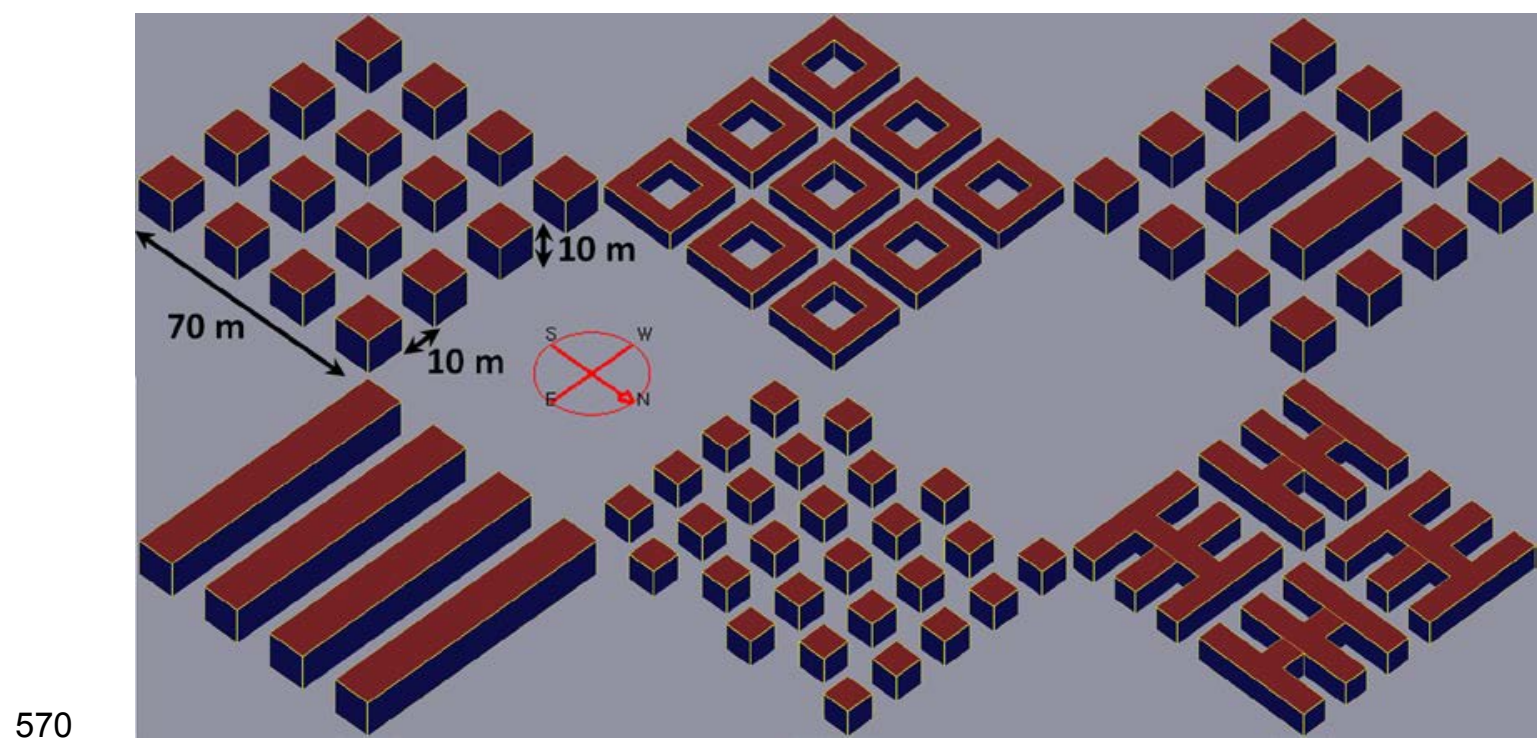

571 Figure 1: The layout and orientation of the urban morphologies under investigation. 

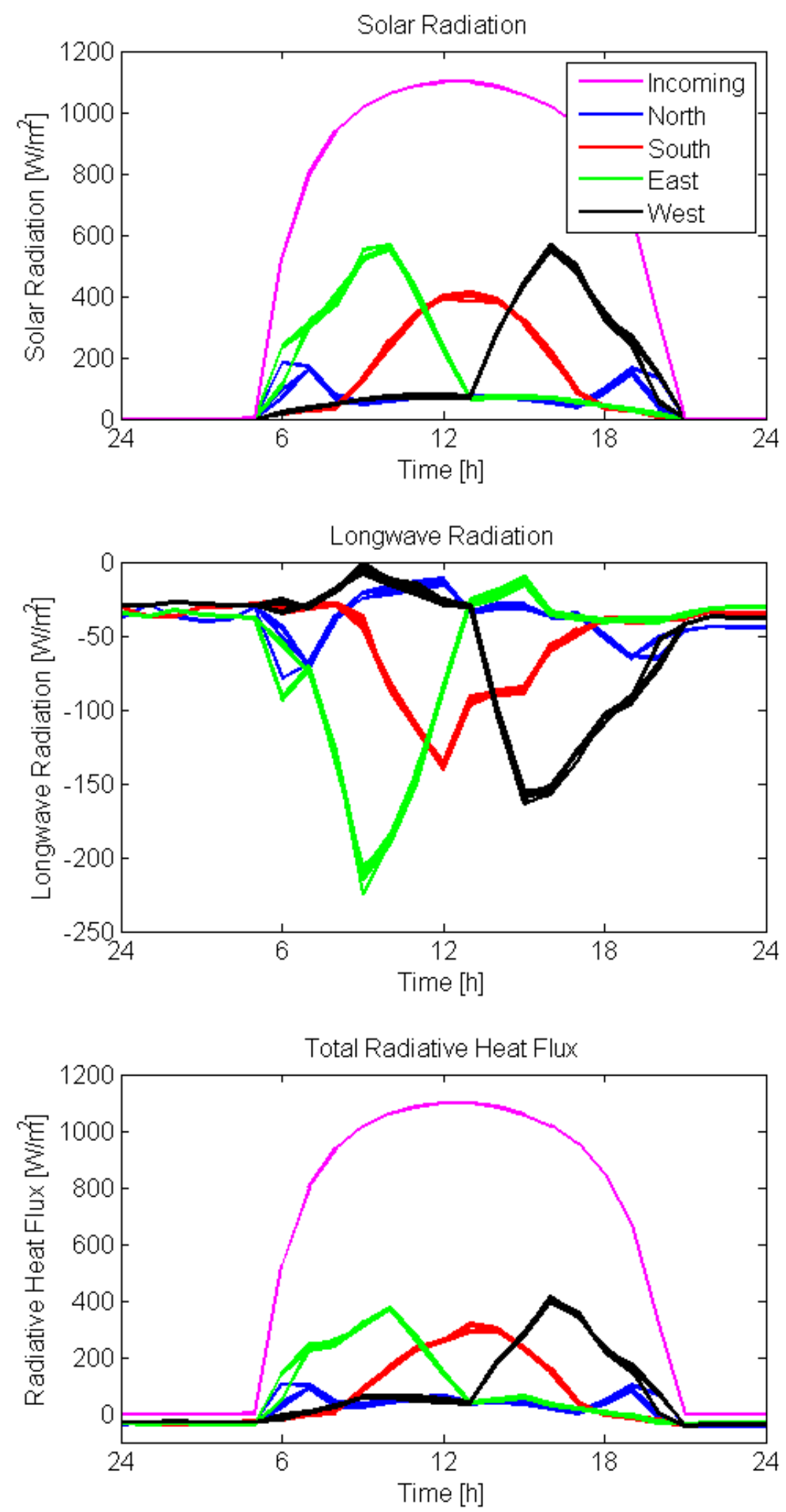

573 Figure 2: Absorbed radiation at the building façades for the case of an array of 16 cubical buildings 574 (see Figure 1). One line is potted for each façade inside the urban area; results are not shown for the 575 façades at the outer boundary of the urban area. Results are for $24 \mathrm{~h}$ in summer with clear sky. For 576 the solar and total radiative heat flux the incoming solar radiation is also given. 

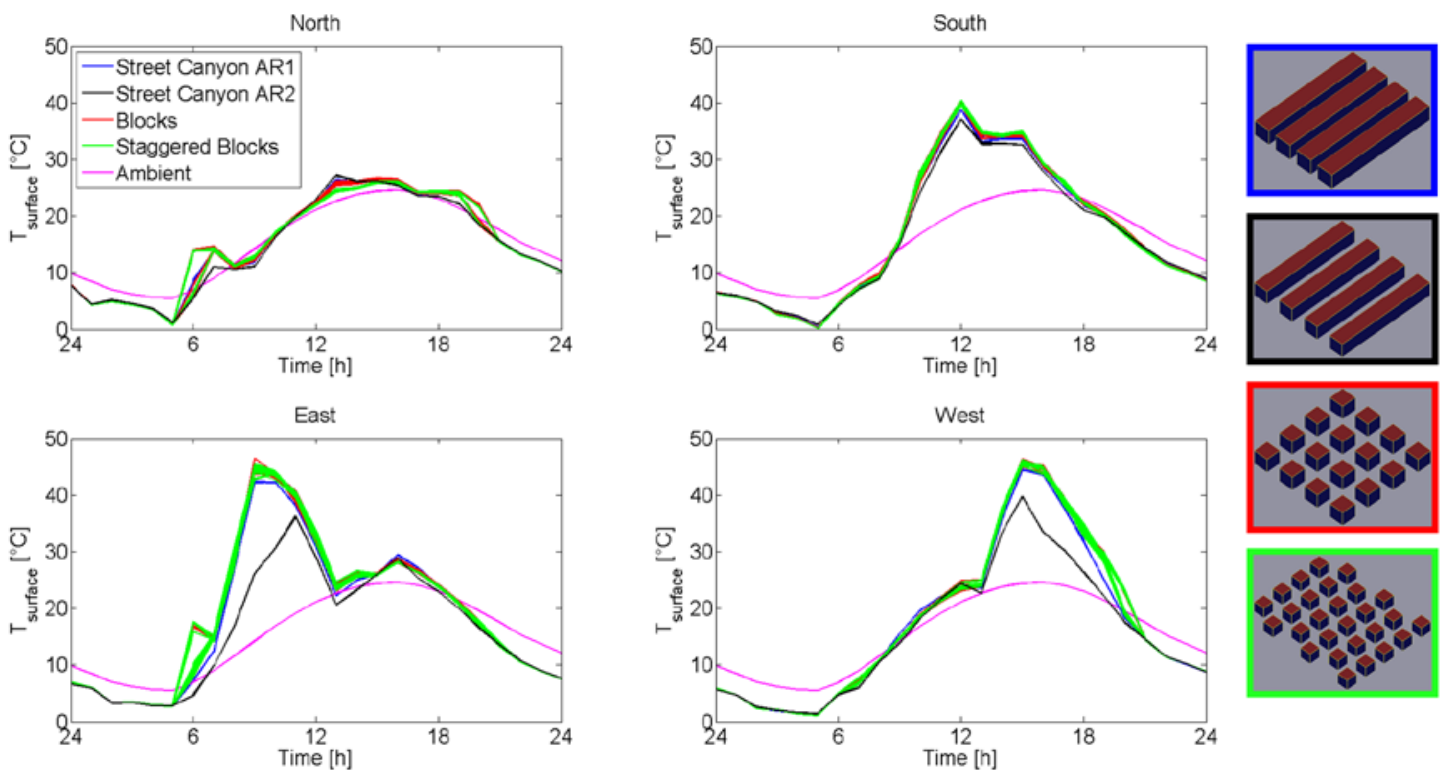

Figure 3: Wall surface temperatures for four different urban morphologies: street canyons with aspect ratios of 1 and 2, aligned blocks and staggered block. One line is plotted for each façade inside the urban area; results are not shown for the façades at the outer boundary of the urban area. Two simulations are conducted for the street canyon cases with two orientations (with a difference of 90 $\left.{ }^{\circ}\right)$ and results are only given for the long façades.
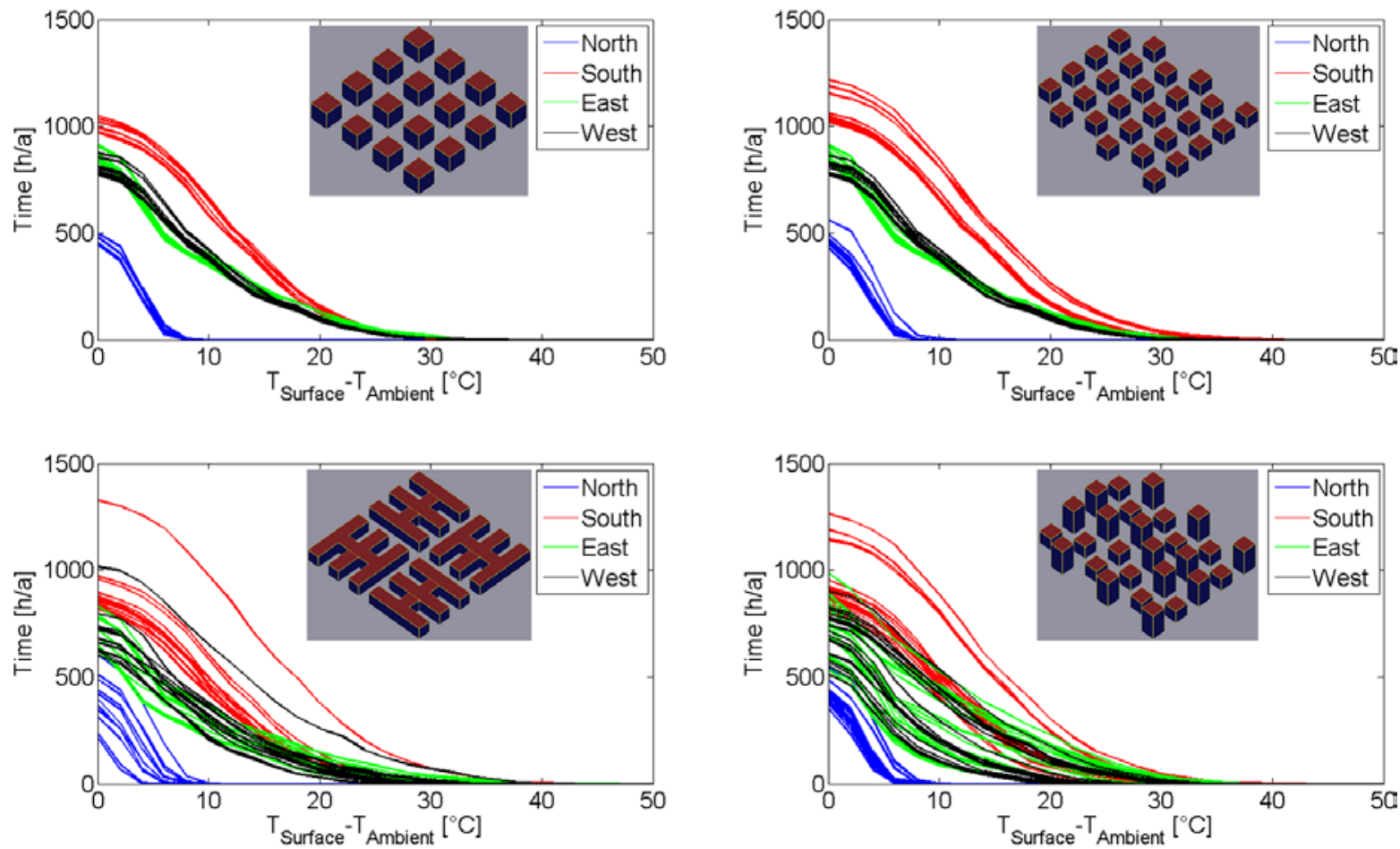

Figure 4: Hours per year that the surface temperature is above $25^{\circ} \mathrm{C}$ and temperature difference between the surface and ambient air is larger than the value on the x-axis. One line is shown for each façade inside four different urban morphologies. 

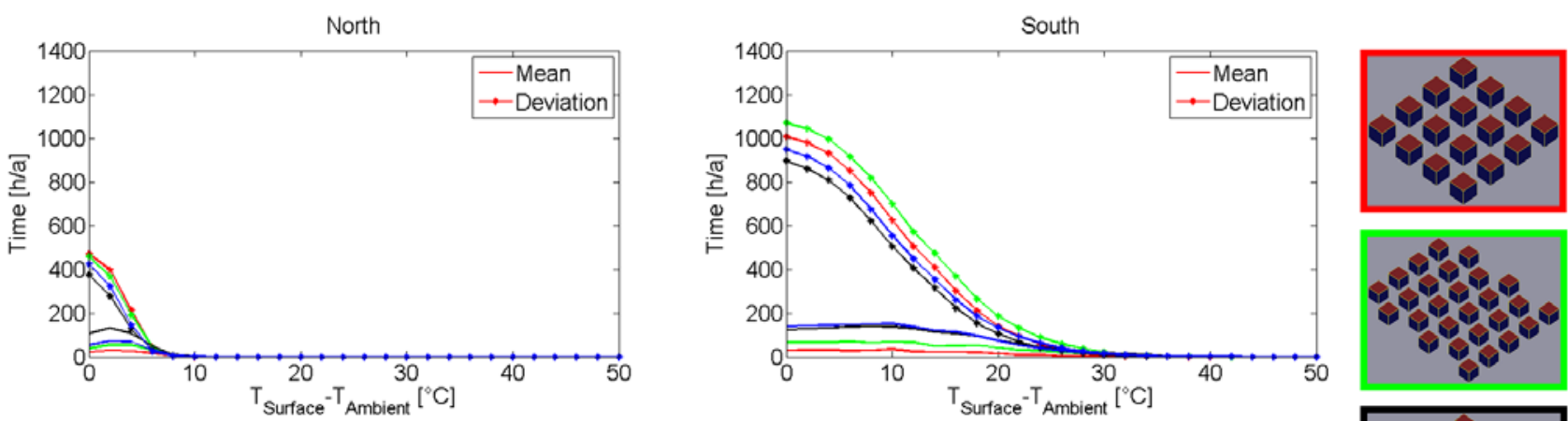

East
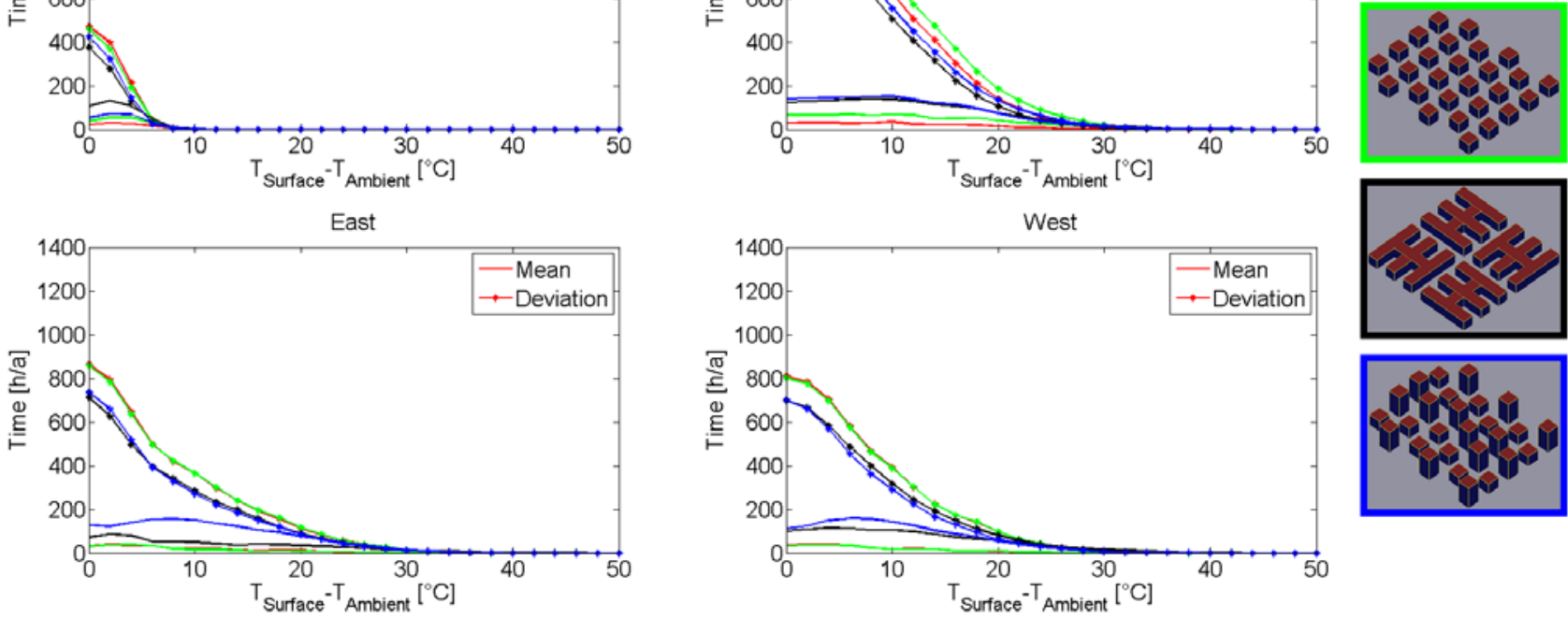

Figure 5: Hours per year that the surface temperature is above $25^{\circ} \mathrm{C}$ and temperature difference between the surface and ambient is larger than the value on the x-axis. For each orientation the mean and the deviation over all façades inside the urban area for each urban morphology are given.
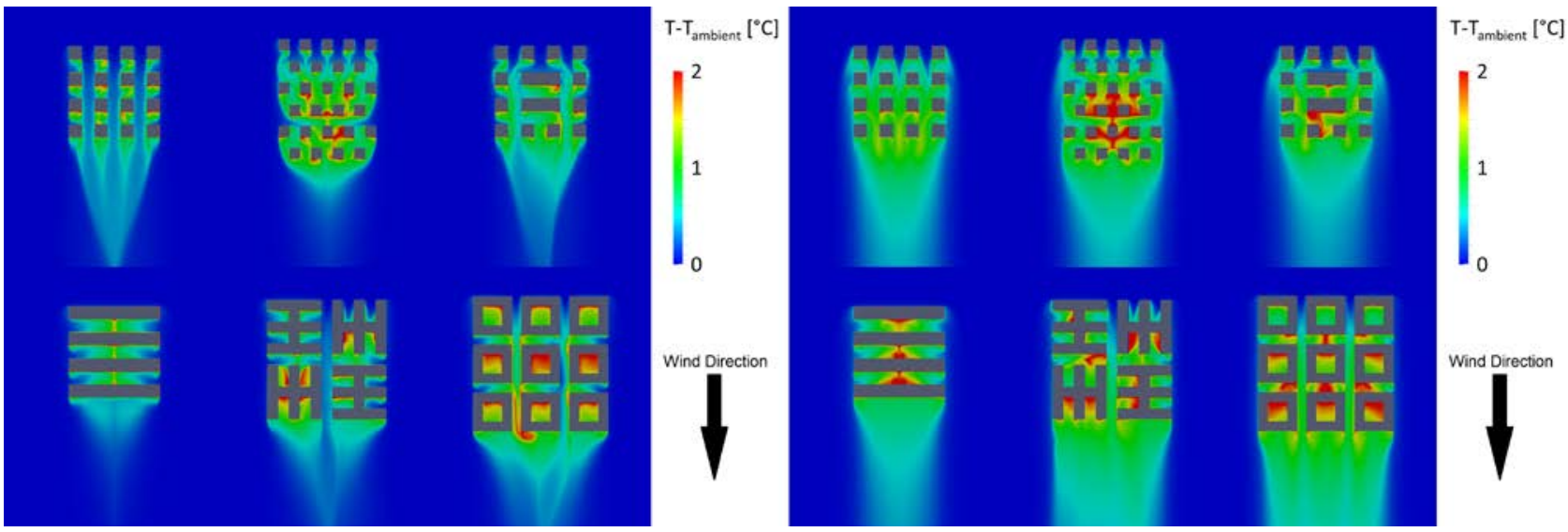

Figure 6: False-colour plots of the temperature difference between the local air temperature and the ambient air temperature at $1.75 \mathrm{~m}$ height for different wind speeds (left: $U_{10}=1 \mathrm{~m} / \mathrm{s}$; right: $U_{10}=5.5$ 
$\mathrm{m} / \mathrm{s})$.

595

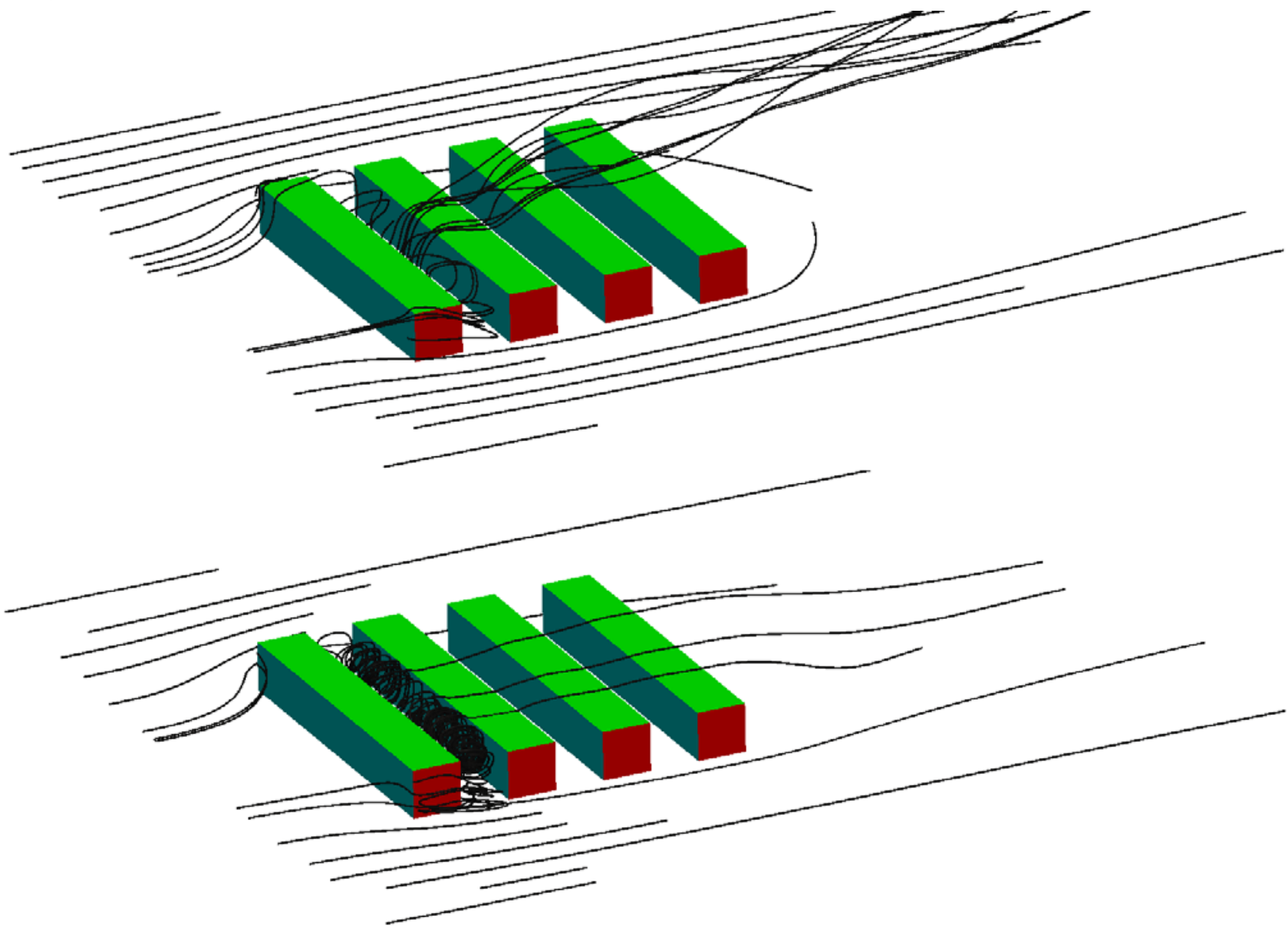

Figure 7: Streamlines for the street canyon case (top: $U_{10}=1 \mathrm{~m} / \mathrm{s}$; bottom: $U_{10}=5.5 \mathrm{~m} / \mathrm{s}$ ).
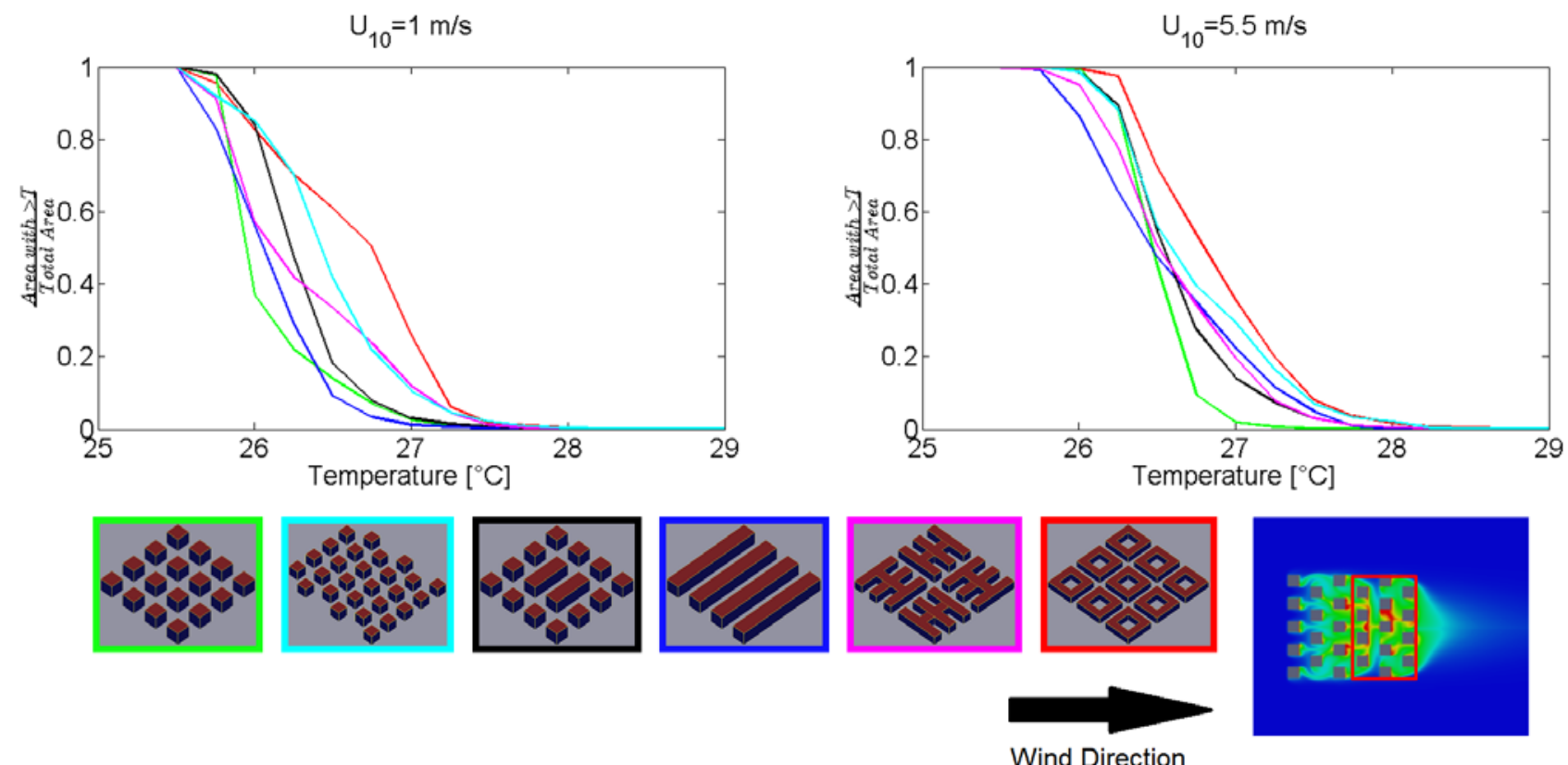

598 Figure 8: Fraction of the area (at $1.75 \mathrm{~m}$ above the ground) which has a higher air temperature than 599 a given value. Only the downstream half of the urban area is considered. 


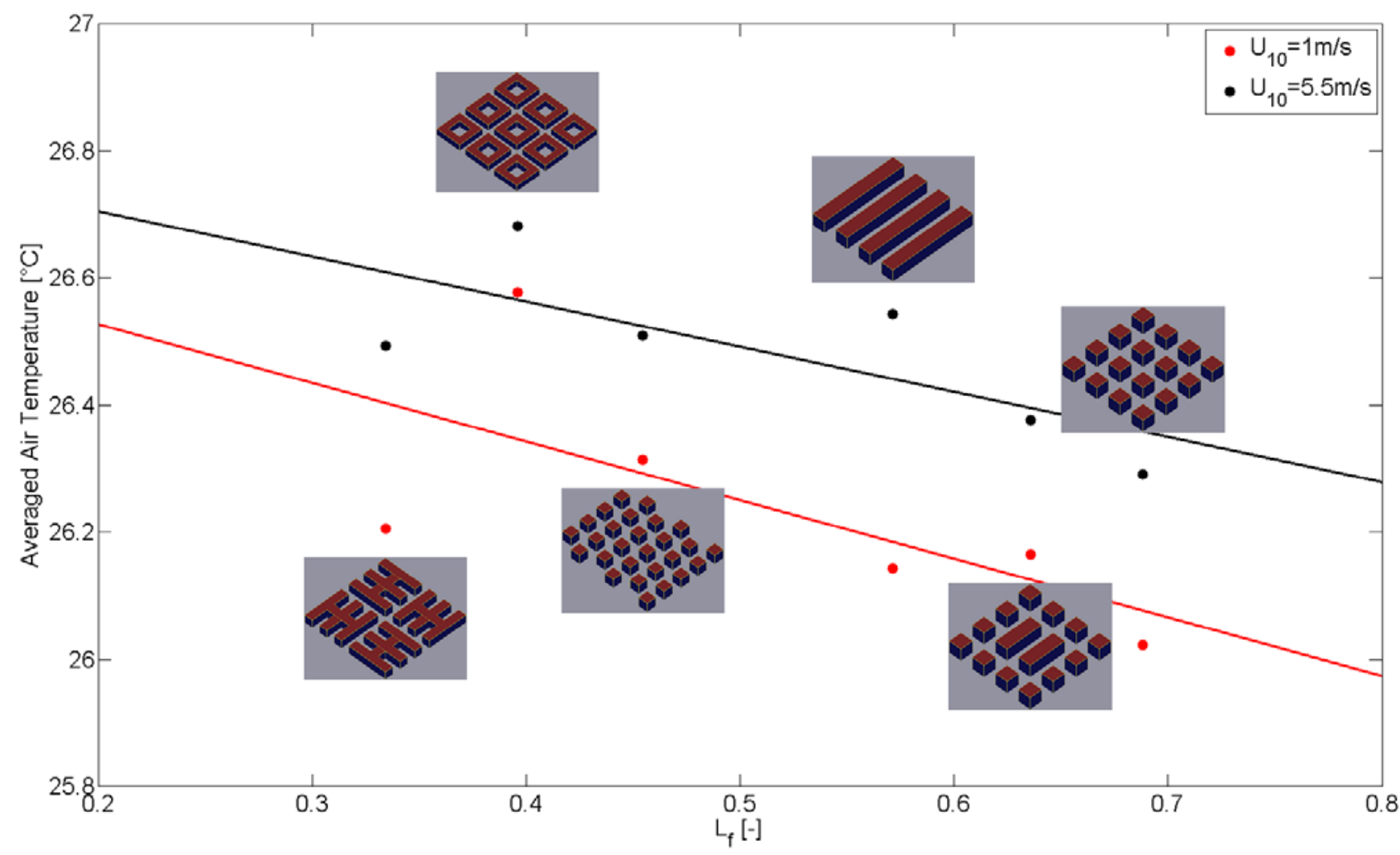

600

601 Figure 9: Averaged air temperature inside the urban area as a function of an area weighted average 602 of a non-dimensional distance between the buildings $\left(\mathrm{L}_{\mathrm{f}}\right)$. The given lines are trend lines.
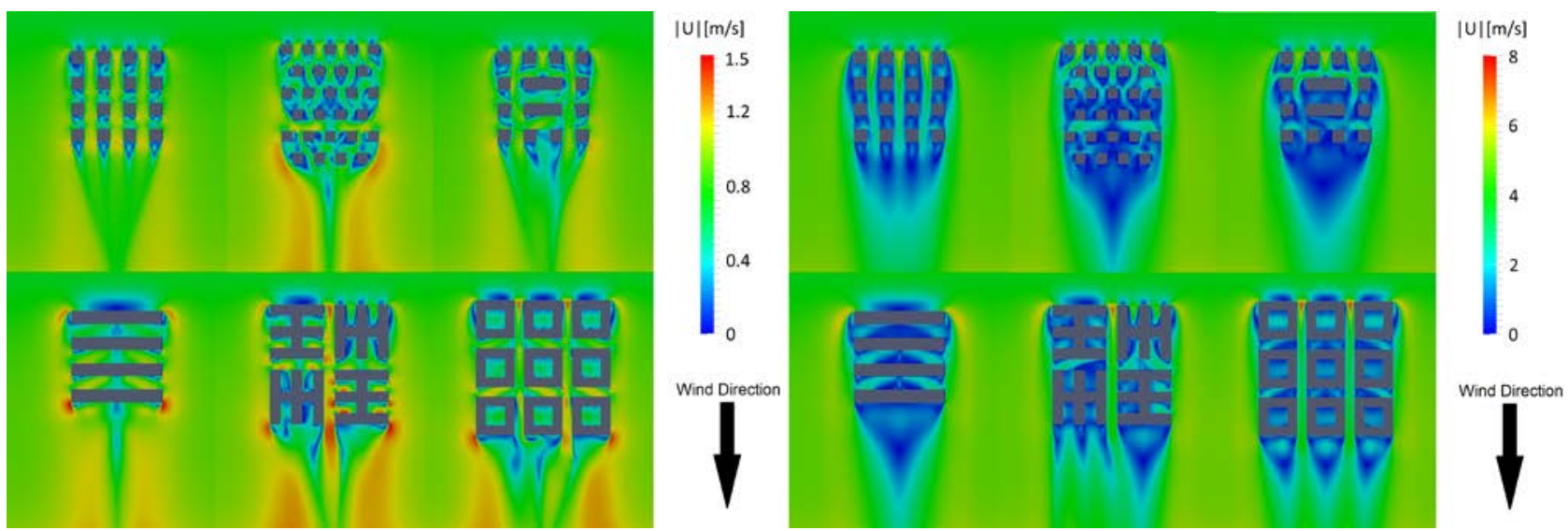

603

604 Figure 10: False-colour plots of the velocity magnitude at $1.75 \mathrm{~m}$ height for different wind speeds 605 (left: $U 10=1 \mathrm{~m} / \mathrm{s}$; right: $\mathrm{U} 10=5.5 \mathrm{~m} / \mathrm{s}$ ). 


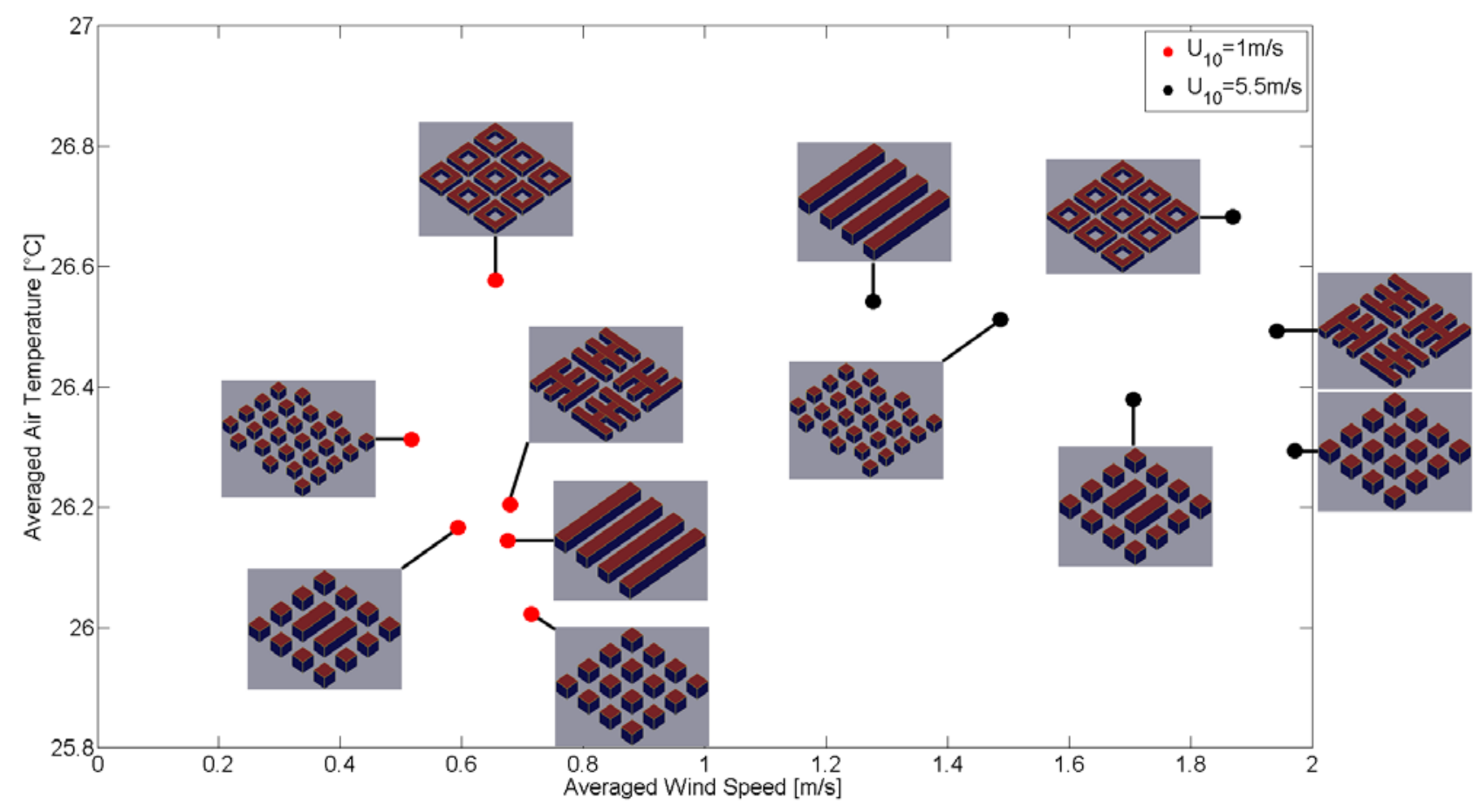

606

607 Figure 11: Averaged air temperatures inside the urban areas as a function of the averaged wind 608 speeds (averages over the whole area) at $1.75 \mathrm{~m}$ height. Results are given for two wind speeds. 